\title{
Són de La Habana: La Ruta de Severo Sarduy
}

Y CANTAN EN LLANO

(caminamos por los jardines del Caslillo de Sceaux-diseñados por Le Notre, estatuas de Puget, residencia campestre de Colbert-, cerca de su apartamento en las afueras de París. Sarduy-los jardines, que repiten basta el borizontic su inexorable geometria, son 'borgianos' dice el escritor-, vive en París dedse bace ya casi diez años. Es ciudadano francés. Cuda uno busca en el otro el verbo qué nos' une: el donde de donde. son los cantantes)

Asediados por una insularidad raras veces paradisíaca, la mayoría de los artistas cubanos notables se ha lanzado tradicionalmente al extranjero, y ha llevado a cabo desde allí obras que con frecuencia han anticipado movimientos artísticos en Hispanoamérica. Desde Madrid, México y Nueva York, José Martí dio los primeros ejemplos en prosa y en verso de lo que llegó a ser el Modernismo. Unos años antes, ese olvidado entre los novelistas del diecinueve, Cirilo Villaverde, terminaba en el exilio neoyorkino la versión definitiva de su Cecilia Valdés, novela cuyos méritos $\mathrm{y}$ anticipos no han sido aún totalmente reconocidos (la primera vetsión es de 1839; Amalia es del 51, María del 67, Cumandí del 71). Y Alejo Carpentier, desde el París de entre guerras y desde Caracas, escribió obras que contribuyeron poderosamente a sacar la narrativa hispanoamericana del callejón sin salida del realismo nativista. José Lezama Lima, para no dejar de ser excepcional también en este punto, ha sido tal vez el único de los grandes artistas cubanos que ha permanecido en la isla a lo largo de toda una vida de creación. Pero la lista de los que no permanecieron sería interminable; baste con añadir a los mencionados los nombres de José María de Heredia (precursor del Romanticismo), Gertrudis Gómez de Avellaneda y Alfonso Hernández 
Catã, muertos todos - México, Fspaña y Brasil respectivamente- en el extranjero.

Al hacer su obra desde París, Severo Sarduy, discípulo y admirador de Lezama, quizás haya venido a compensar por la inmovilidad del maestro. ${ }^{1}$ Lo cierto es que, como ocurriera con la obra de Martí y hasta hace muy poco con la de Lezama, la obra de Sarduy se ha adelantado tanto a la de sus contemporáneos hispanoamericanos que, con las excepciones de rigor, la crítica apenas ha empezado a reconocer el valor, la riqueza y la novedad del joven narrador cubano. En comparación con García Márquez, Cortázar, Fuentes, y hasta jóvenes como Manuel Puig, Sarduy es un escritor secreto, a pesar de que sus libros, como los de los autores mencionados, han aparecido en editoriales de gran difusión: Gestos en Seix Barral (1963), De donde son los cantantes en Joaquín Mortiz (1967) y Escrito sobre un cuerpo en Sudamericana (1969). Pero conviene recordar que sólo los escritores secretos -el Borges de los cuarenta, el Vallejo de los treinta, el Neruda de las Residencias- han logrado mantener viva a lo largo de los años una llama incandescente, mientras que las luminarias, como el propio Carpentier y tal vez Asturias, han destellado fugazmente para ser relegados luego, estrellas fijas en su luz, al panteón de los clásicos. Para suerte suya, Sarduy no corre por ahora ese riesgo.

Nacido en Camagüey en 1947, donde reside hasta los diecinueve años, Ja vida de Sarduy ha sido, según declaración propia a Emir Rodríguez Monegal, una especie de 'viaje', viaje que lo ha llevado, primero a Ia Habana del batistatc, luego a La Habana de los primeros momentos del triunfo de la Revolución, y después al París del apogeo estructuralista. ${ }^{2}$

Al llegar a La Habana en 1956 (para estudiar medicina) Sarduy se vincula con cl grupo de la revista Ciclón, en la que ya había publicado algunos poemas enviados desde el interior. Hay que recordar que la revista Ciclón, dirigida por José Rodríguez Feo, había surgido de la ruptura de éste con Lezama Lima y el grupo de la célebre Orígenes; pero, no obstante el tono más irreverente y experimental de la nueva revista (en ella publicaría Cortázar fragmentos de sus Historias de Cronopios $y$ de Famas) que la apartaba del 'trascendentalismo hermetista' de Ori-

1 Para más detalles sobre la relación entre Sarduy y Lezama consultar: Severo Sarduy, "Dispersión / falsas notas' (homenaje a Lezama)," Mundo nuevo, No. 24 (junio de 1968), págs. 5-17; "Un Proust cubain", La Quinzaine littéraire, No. 115 (1-15 de abril de 1971), págs. 3-4; y las dos entrevistas de Sarduy con Emir Rodríguez Monegal en: Mundo nuevo, No. 2 (agosto de 1966), págs. 15-26 y Revis. ta de Occidente, No. 93 (diciembre de 1970), págs. 315-343.

2 Mundo nuevo, 2, p. 15. 
genes, las contribuciones de Sarduy están todavía imbuidas de la poética 'lezamesca', como puede observarse en el siguiente poema de 1956:

\section{OTRO}

Otro ángel suspendido salmodiaba:

soy asexual y etéreo, la raza que me habita

ha enemistado con el tiempo. El mar

- de extraña perennidad mi centro herido-

anegándome de ajeno rumor, de esos

contornos en que muere poblado, de la aciaga

voluntad con que su azar a veces nos persigue.

Espejeando su cábala provocado ha

por medio de ciertas complejas palabras

las fuerzas que lo aman. Invitando

a destruir, a repartir la noche que lo habita.

$\mathrm{Oh}$, tu oscuro dominio. ¿Hasta dónde

seremos tu ciudad ? 3

Los poemas publicados en Ciclón ya le valen a Sarduy menciones (sólo como poeta desde luego) en el Bosquejo bistórico de las letras cubanas de José Antonio Portuondo (1962) y en el Panorama bistórico de la li. teratura cubana de Max Henríquez Ureña (1963).*

La segunda escala del 'viaje' de Sarduy también fue en La Habana, pero ahora en La Habana de la euforia y confusión revolucionarias de 1959. Durante ese año y parte del siguiente, Severo Sarduy colaborará en tres publicaciones, "Nueva generación", página literaria del periódicc Revalución (órgano del 'Movimiento 26 de Julio'), Lunes de Revolución, suplemento que reemplazará la página mencionada, y Diario Libre, donde dirige una sección de crítica. ${ }^{5}$ La primera contribución de Sarduy

3 Ciclón, Vol. 2, No. 3 (mayo de 1956), p. 49.

4 José Ántonio Portuondo, Bosquejo bistórico de las letras cubanas (La Haba. na: Editorial del Ministerio de Educación, 1962), p. 73; Max Henríquez Ureña, Panorama bistórico de la lizeratura cubana (1492-1952) (Nueva York: Las Américas Publishing Co., 1963), Vol. 2, p. 447.

5 Me ha sido imposible consultar el Diario Libre. Según el autor: "Diario Libre fue una página diaria dirigida en colaboración con Manuel Díaz Martínez, Rajmundo Fernández Bonilla y Frank Rivera durante casi todo el año 1959". Carta de Sarduy al autor, París, mayo de 1971. El periódico Revolución empezó a publicarse clandestinamente durante la lucha armada contra Batista y después del 1 de 
después del 1 de enero de 1959, fecha de la caída de Batista, es del 13 de enero (en "Nueva generación"); Fidel Castro había hecho su entrada triunfal en La Habana apenas cinco días antes. El título de su primer trabajo, así como los de algunos de los otros que aparecen durante la corta vida de "Nueva generación" -enero y febrero-, indican ya el nuevo tono político - 'comprometido'- de la obra sarduyana: "Dos décimas revolucionarias", del 13 de enero (que según aclaración del periódico habían circulado clandestinamente), "Pintura y revolución", ensayo del 31 de enero, "El torturador", 'cuento cubano' del 6 de febrero. ${ }^{6}$ Pero es en Lunes de Revolución donde Sarduy publica sus trabajos más importantes de la época. Este suplemento literario, dirigido por Guillermo Cabrera Infante (y donde fueron acogidos algunos de los colaboradores de la ya difunta Ciclón), es un hito importante en la evolución de la literatura cubana contemporánea. José Antonio Portuondo ha caracterizado el suplemento de la siguiente manera en su Bosquejo bistórico de las letras cubanas:

Las páginas de Lunes de Revolución vibraron, durante dos años [hasta agosto de 1961 cuando se celebra el Primer Congreso $\mathrm{Na}$ cional de Escritores y Artistas Cubanos], con las producciones en prosa y verso, rebeldes en su mayoría, ardientemente polémicas e inconoclastas no pocas, transidas de inquietud política ... con que los jóvenes trataban de encontrar la expresión adecuada a la nue. va y todavía no bien definida entonces, concepción de la realidad determinada por la Revolución... De ahí el tono de violencia un tanto anárquica, de insistencia en la faena destructiva y acerbamente

enero de 1959 circuló diariamente hasta ser unido con su rival, Hoy, órgano del Partido Comunista, bajo el nombre de Granma. Para más detalles ver: Andrés Suárez, Cuba: Castroism and Communism, 1959-1966 (Cambridge, Massachussets: The M.I.T. Press, 1967), págs. 32, 108, 172-3 y 230.

6 Revolución, 13 de enero de 1959 p. 5; ibid., 31 de enero de 1959, p. 14; ib:a., 6 de febrero de 1959 , p. 15. He aquí una de las décimas como ejemplo del tono político que menciono:

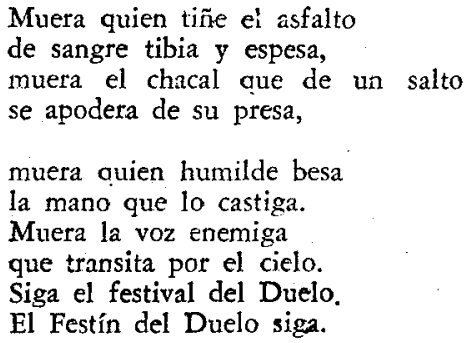


crítica, antes que en la constructiva y organizadora, en la reiteración de modos peculiares del período del clandestinaje y la lucha armada ... Alli se dieron a conocer, entre otros, prosistas y poetas de indiscutible talento como Roberto Branley, José Alvarez Baragaño, Humberto Arenal, Carlos M. Luis, Calvert Casey, Julio Matas, Pedro de Oráa, Heberto Padilla, César Leante, Roberto T. Escardó y muchos más. ${ }^{7}$

No faltan, sin embargo, colaboraciones de escritores consagrados como Alejo Carpentier, Lezama Lima y Virgilio Piñera, así como las de jóvenes que ya despuntaban como Roberto Fernández Retamar, lo cual da a Lunes de Revolución un aspecto de mosaico - de generaciones y de tendencias ideológicas-, que le imprime un sello indistintamente de transición. Es revelador que los trabajos de Sarduy para Lunes de Revolución, salvo dos poemas en un número homenaje a Ballagas y dos más en un número dedicado a los escritores de Camagüey, sean reportajes y críticas de arte: "La revolución de un pintor: homenaje a Víctor Manuel", del 5 de octubre de 1959; "En casa de Mariano", del 12 de octubre; "El salón nacional de pintura y escultura", del 19 de noviembre; "La bienal de Venecia", del 27 de junio de 1960, y "Picaso expone", del 15 de agosto del mismo año. ${ }^{8}$ Es precisamente en este período de transición que se empieza a fraguar Gestos, su primera novela, obra que habría de eclipsar su labor de poeta para reclamarlo, al parecer definitivamente, como narrador (sus únicos relatos hasta la fecha en que se publica Gestos son, que yo sepa, "Las bombas", "El general" y el "cuento cubano' "El torturador", todos aparecidos en "Nueva' generación" a principios de 1959).9

7 Bosquejo, p. 76.

8 "De este modo: homenaje a Ballagas", Lunes der Revolución, No. 26 (14 de septiembre de 1959), p. 11 (dos sonetos); "La revolución de un pintor: homenaje a Víctor Manuel", ibid., No. 29 (5 de ocutbre de 1959), págs. 8-9; "En casa de Mariano", ibid., No. 30 (12 de octubre de 1959), págs. 3-5; "El salón nacional de pintura y escultura", ibid., No. 31 (19 de octubre de 1959), págs. 2-4; "La bienal de Venecia", ibid., No. 65 (27 de junio de 1960) p. 23; "Picasso expone", ibid., No. 72 (15 de agosto de 1960), págs. 16-17.

9 "Las bombas", Revolución, 19 de enero de 1959, p. 15; "El general", ibid., 27 de enero de 1959, p. 15; "El torturador", ibid., 6 de febrero de 1959, p. 15. Sarduy ha publicado en los últimos años algunos poemas en: Tel Quel, No. 23 (otoño de 1965), oágs. 83-88; Zona franca, Año II, No. 30 (febrero de 1966), págs. 14-15. En el número especial de Lunes de Revolución dedicado a los escritores de Camagüey (19 de septiemóre de 1960) se anuncia que Sarduy tenía planeado recoger sus poemas en forma de libro. Lo ha hecho, parcialmente, en dos 'libros-objeto' publicados en Alemania, Flamenco (1969) y Mood Indigo (1970). 
En 1960 Sarduy viaja a Europa, becado por la Dirección de Cultura para estudiar crítica de arte en París. Esta, la tercera escala, en su viaje ha sido la más larga y productiva, y se refleja no sólo en sus novelas, sino también en su colaboración en dos revistas radicadas en París durante esos años, Tel Quel, órgano de un importante grupo estructuralista reunido alrededor del crítico Philippe Sollers y Mundo nuevo que en su 'primer época'. (hasta el número 25; julio de 1968), fue dirigida por Emir Rodríguez Monegal.

La experiencia revolucionaria en Cuba sacude violentamente las ideas de Sarduy. Derrumbada ya para él la 'ideología burguesa' sobre el arte, tampoco le atrae el realismo socialista o sus derivados, como evidencian estas líneas del 31 de enero de 1959:

Señores, sé que padecemos la fiebre de criterios que caracteriza todas las post-revoluciones. Me explico: queremos arte figurativo, cuadros que "signifiquen" algo, que den opiniones... Adivino que dentro de cinco años nuestra ciudad estará llena de murales con soldados aplastando bajo sus botas mujeres tuberculosas, de lienzos de jóvenes que hablan de cultura popular roja (o amarilla), de poemas "objetivos" donde aparezcan prostitutas de quince años y bombardeos ... Pues bien, yo digo que todo esto es inútil. Digo que ya es tarde. La Pintura Popular, el Arte Objetivo tuvo que haberse hecho antes. Si Cuba hubiera tenido una figura como Diego Rivera, no hubiera habido Dictadura... Sí, queremos arte nacional, pero puede hacerse pintura nacional sin llenar los cuadros de guajiros y palmas, puede hacerse teatro nacional donde no aparezcan gallegos y negritos, puede hacerse poesía nacional que no cante a los turis. tas y a los soldados. . .

El contacto con el grupo Tel Quel, sobre todo con Roland Barthes, a cuyos cursos en la Ecole Pratique des Hautes Etudes asiste, Sarduy, viene a llenar el vacío teórico que la sacudida revolucionaria había dejado en Sarduy. Vacío, o tal vez confusión, ya que, si seguimos los pasos de Sarduy desde 1956, sorprenderemos en su obra resonancias de muy variadas y a veces contradictorias doctrinas estéticas. En sus poemas, como ya queda dicho, salta a la vista la influencia de Lezama Lima, poeta, no hay que olvidarlo, católico (lo cual explica mucho más de la obra del autor de Paradiso de lo que la crítica por lo general ha consignado); pero no dejan de aflorar también en esos primeros poemas ecos existencialis-

10 "Pintura y revolución", Revolución, 31 de enero de 1959, p. 14. 
tas - "y se iluminó la Nada", "Voy a crearte para que cuando muera/ perdures implacable vigilando la nada", etc. ${ }^{11}$ - y en los escritos de 1959 y 1960, como también ha sido ya apuntado, hay una tentativa bastante clara de hacer literatura 'comprometida'. En cualquier caso, en Tel $Q u e l$ Sarduy logra hallar una teoría que le permite, por un lado, dar rienda suelta al barroquismo lezamiano del cual nunca ha de desprenderse, y a la vez producir una literatura que no esté sujeta a ideologías, sin ser por ello trascendentalista o escapista. Sarduy ha explicado así a Rodríguez Monegal las posiciones tomadas por el grupo Tel Quel ante la literatura:

La revista Tel Quel y los jóvenes agrupados alrededor de Sollers han partido, creo, del hecho de tomarse muy en serio la literatura. Ellos rechazaban la literatura como algo respaldado por 'lo que se dice', lo descrito, el mensaje, etc. Ellos no pensaban, como se piensa con mucha frecuencia entre los narradores de nuestra América, que el mensaje basta para escribir bien. Luego poco a poco se fueron acercando, fueron estudiando lo que constituye la literatura; qué organización particular del lenguaje, qué trabajo sobre el significante, y yo diría, empleando esa palabra en su verdadera acepción, qué retórica.. . Luego Sollers y sus amigos llegaron a pensar que la escritura, cuando parece decir otra cosa, si es verdaderamente escritura, lo primero que refleja es eso: el acto de escribir, con sus estructuras propias y su dimensión según creo ontológica. ${ }^{12}$

Dos han sido, pues, los preceptos de las teorías de Tel Quel que guían a Sarduy en esos años en que escribe su segunda novela, $D e$ donde son los cantantes, y termina su tercera, Cobra, de la cual ya ha publicado capítulos sueltos: 1) la autonomía de la escritura, o sea, la escritura como sistema específico sujeto a cus propias leyes, no circunscrita a un significado, sino abierta a una multiplicidad de significados. En De donde son los cantantes. La proliferación de significados crea tantos espejos linguísticos que éstos acaban por reflejarse mutuamente, erigiendo así un espacio fiticio hacia el cual no podemos extender la mano sin tropezar con la superficie dura de ese engañoso cristal - la palabra. La tetórica de la ficción es en Sarduy, parafraseando el título del conocido libro de Booth, retórica. 2) La organización del subconciente como discurso; es decir, la estructuración de todo conocimiento como un lenguaje que enmascara la

11 Ciclón, ap. cit. p. 50 .

1s Mundo nuevo, sp. cit., p. 25. 
falta de sujeto, que crea (he aquí la dimensión ontológica de que hablaba Sarduy) una persona allí donde se manifiesta su ausencia. Como ha dicho Jacques Lacan, cuyas teorías sobre el sicoanálisis están intimamente ligadas a las teorías del grupo Tel Quel: "L'inconscient n'est pas subliminal, faible clarté. Il est la lumière qui ne laisse pas sa place a l'ombre, ni s'insinuer le contour. Il représente ma reptésentation là où elle manque, où je ne suis qu'un manque du sujet", ${ }^{13}$ La novela se convierte así en representación de una representación de una representación, aboliendo a su autor, que queda sumido en el lenguaje, en el discurso que "se habla a través de él". Todo ello le permite a Sarduy ser autóctono y salvaje, sin cantar a soldados y a turistas.

Mundo muevo representa para Sarduy la entrada en el plano internacional de la literatura hispanoamericana. Su colaboración en esta revista, que empieza desde el primer número (julio de 1966), le permite figurar en las mismas páginas que los novelistas consagrados, o en vías de consagración en Mundo nuevo, que formaton lo que ha pasado ya a la historia como el Boom de la narrativa hispanoamericana: Carlos Fuentes, que publica fragmentos de Cambio de piel, Gabriel García Márquez, que publica dos largos fragmentos de su obra maestra, Cien años de soledad, Guillermo Cabrera Infante, que colabora con páginas de sus Tres tristes tigres, Guimarâes Rosa, que publica fragmentos en castellano de su gran obra, Grande Sertâo: veredas, y tantos otros como José Lezama Lima, José Donoso, Manuel Puig, Gustavo Sáinz, etc. Además de sus trabajos de crítica, que luego se convertirán en Escrito sobre un cuerpo, y algunos de los cuales aparecen primero en francés en Tel Quel, Satduy a su vez publica en Mundo nuevo dos fragmentos de la entonces inédita $D e$ donde son los cantantes. Como tantos escritores hispanoamericanos antes que él, Sarduy encuentra en París, sobre todo en su contacto con el grupo congregado alrededor de la redacición de Mundo nuevo, a sus verdaderos compatriotas - a esos otros desterrados que como él encuentran entre sí los reflejos necesarios para asegurarse del valor de sus propias existencias y vocaciones.

CON SU TROVA FASCINANTE

("Qué grande fue el Beny! el Conde Negro; que profundos los años 50 de Cuba: en el podridero, en los bongos, la orquidea mejor, inmaculada, 36, n. 1 .

1s "La méprise du sujet supposé savoir", Scilicet, Vol. I, No. 1 (1968), p. 
qué lirismo, perdona." Carta de Severo Sarduy al autor. Paris, enero de 1971)

Utilizando procedimientos del nouveau roman, como no se ha cansado de repetir la crítica, Severo Sarduy ofrece en Gestos (1963) una visión despiadada, pero a la vez lírica de La Habana de los años cincuenta. En este sentido Gestos es típica de las novelas cubanas de los primeros años de la década pasada - por ejemplo, Juan Arcocha, Los muertos andan solos (1962), Edmundo Desnoes, No bay problema (1961), Jaime Saruski, La búsqueda (1962), César Leante, El perseguido (1964), Virgilio Piñera, Pequeñas maniobras (1963) -; novelas todas que volvieron la vista sobre La Habana del batistato con mórbida fascinación y a veces con extraña nostalgia. Como ha señalado J. M. Caballero Bonald en la introducción a su antología, Narrativa cubana de la revolución:

La mayor parte de la literatura que aparece inmediatamente después de 1959, o bien había sido escrita años antes y aguardaba que fuese factible su circulación, o correspondía a la perentoria necesidad de dejar zanjado el recuento de un mundo abolido, acusándolo moralizadoramente desde el que empezaba a forjarse. En líneas generales, el censo de la narrativa cubana de este primer tramo de la revolución se inclina con significativa insistencia hacia la denuncia del pasado inmediato; apenas fija su atención en el despertado presente. ${ }^{14}$

Algo similar había ocurrido en la narrativa cubana posterior al machadato, que se inspiró insistentemente en sucesos ocurridos en La Habana de los años treinta (por ejemplo, El acoso de Alejo Carpentier).

Pero La Habana de los treinta of recía posibilidades literarias muy diferentes a las ofrecidas por la de los cincuenta. Mientras que la agitación política y la violencia de aquélla podían eclipsar el más desaforado esfuerzo imaginativo, ésta permaneció relativamente aislada de la conmoción revolucionaria casi hasta el momento mismo de la caída repentina, y para muchos habaneros sorpresiva, de la dictadura. A pesar, o tal vez a causa del terrorismo esporádico y la represión policíaca que le servían de 'avisos de muerte', La Habana se lanzó desenfrenadamente a la frivolidad y el placer con un intenso espíritu de carpe diem. Los cincuenta son los años del triunfo apoteótico de cantantes populares como Beny Moré y de orquestas de cha cha cha (el nuevo ritmo), como La Aragón de Cienfuegos, y sobre toda del apogeo de la televisión, que

14 (Madrid: Alianza editorial, 1968), p. 13. 
difundió, como nunca antes, las fabulosas posibilidades de la sociedad de consumo en gran escala. Es ésta además la época de las grandes campañas publicitarias para fomentar el turismo, que, entre otros (como el crecimiento de la clase media), fueron factor decisivo en el florecimiento de grandes nightclubs ccmo el célebre Tropicana (inmortalizado por Cabrera Infante), que aceleraron el ritmo de la vida nocturna habanera-notoria ya desde la Colonia por la gran actividad del puerto. Con las guerrillas en un Oriente lejano, casi mítico, y del que se sabía poco a causa de la censura, La Habana, como el Berlín de los últimos años de la guerra, se abandonó furiosamente a la vida para exorcisar a la muerte. Son estos "encantos de la culpa" calderonianos, esta mezcla quevedesca de lo grotesco y lo sublime, de júbilo desaforado premonitorio de la muerte, lo que cautiva a los novelistas de los primeros años del castrismo; quienes, además, se sentían impelidos a escribir literatura comprometida cuando la Revolución ya había triunfado y hacía por institucionalizarse. obviando así momentáneamente la posibilidad de escribir sobre la situación actual.

Esa Habana es la que aparece en novelas tan disímiles (y de méritos tan desiguales) como La situación de Lisandro Otero, Gestos, y sobre todo, Tres tristes tigres de Guillermo Cabrera Infante (cuya primera versión, Vista del amanecer en el trópico, es de 1964). Es también el mundo alucinante que encontró en la primera escala de su viaje el bachiller camagüeyano Severo Sarduy.

Así, en un primer plano, Gestos describe los últimos pasos de esa danza de la muerte que baila la gran metrópoli amenazada por la violencia de la guerra y el derrumbamiento inminente de su ritmo de vida. Lo efímero y teatral de la vida carnavalesca de la ciudad se subraya en páginas que manifiestan obvias reminiscencias del barroco español de Quevedo y Calderón: "Las telas desteñidas y los papeles chinos de un rosado que debió ser escarlata cubren carrozas empañadas y las retorcidas orlas de yeso. El aguacero repentino ha arrancado la pintura lumínica, los esmaltes baratos, el oro demasiado abundante para ser legitimo." (p. 61). En este plano -que pudiéramos llamar, referencial-, Gestos es también una novela 'comprometida' en la que no faltan alusiones a lacras sociales: "Los negros de La Habana nunca cesan. ... No cesan porque no tienen trabajo, por eso no cesan de cantar. Van y vienen a todas horas, van y vienen siempre cantando, y a veces se detienen para tomar un poco de café, para apuntar a veces algunos números, y luego, siempre cantando. pasar de un lado a otro, de un lado a otro de la calle. Siempre cantando entre tirada y tirada." (p. 12) Y en páginas de denuncia, únicamente 
igualadas en los cuentos de Asi en la paz como en la guerra de Guillermo Cabrera Infante, se describe con brutal objetivismo la represión policiaca:

Los azules bien armados, ordenados, y claro está, disparan. Al aire, al principio, luego un hombre cae muerto. Los otros se van. Han desaparecido. Ahora la esquina está sola; los azules, a pasos seguros, mesurados, se van acercando a la base de la torre. Son hombres parecidos, delgados, musculosos. Se desplazan por movimientos simétricos; uno de ellos toma en sus manos el niple, lo entrega a otro; éste camina decidido, inmutable, siguiendo una ruta ya prefijada, con un automatismo de trabajo rutinario, hacia el hombre que yace sobre la acera; un tercero, que espera, alza el brazo derecho del hombre, un cuarto toma el niple y lo coloca en la mano del hombre. Se apartan. El último policía avanza, toma la foto. (p. 50)

Reflejan claramente estos pasajes de la novela las preocupaciones de Sarduy durante el período de la lucha armada contra Batista y los primeros meses después del triunfo de la Revolución, como puede comprobarse al cotejar un fragmento de un ensayo-relato intitulado "Las bombas" (publicado en "Nueva generación" el 19 de enero de 1959), con una página de Gestos:

Comenzó la época de las bombas. Diariamente se reportaban heridos de gravedad y aparecieron los primeros muertos. Las bombas eran tema de actualidad: se comentaban en los cafés, en la casa, en el boxec y se empezó a hablar del asunto hasta en los círculos literarios. Estos últimos, dada su predilección por la originalidad, fueron a su vez los primeros en abandonar el tema, el cual se fue olvidando en los otros círculos hasta que las bombas se tornaron en sucesos cotidianos. ... Pero toda esta tragedia, toda esta angustia, toda esta masacre - lo confieso con valentía - comienza a fatigarnos. El aburrimiento amenaza de nuevo. Volveremos a la canasta. ${ }^{15}$

En Gestos aparece el mismo tema, pero ahora se dramatiza, con un magistral juego de paréntesis, su penetración insidiosa en la conversación diaria, y la fusión de la tragedia con los sucesos más anodinos de la vida de la ciudad:

Hoy han comenzado las bombas (deme un café). Ha comenzado la guerra en Oriente (café, por favor) y ahora la cosa sí que va en

15 Revolución, 19 de enero de 1959, p. 15. 
serio (no joda, deme un café) dicen que tienen hasta aviones (un café, coño) que van a venir en una invasión.

Un café, por el amor de Dios (la bomba de anoche). Si no le es molestia, un café (dicen que fue enorme). Yo preferiria café, con este calor no hay otro remedio (ha leído usted los periódicos). Cómo toma usted café (pero tú todavía crees en los periódicos)... Hoy explotó la primera bomba (hoy explotó la primera bomba). Un café (p. 22).

En fin, los 'gestos' son -en este plano- las muecas de abatimiento a que son reducidos los personajes en un complejo amoiente urbano de creciente caos y violencia: "La columna de humo empaña el cielo. Una mujer negra huye, descalza con un pedazo de hielo envuelto en papel de périódico; alza el paquete y salta sobre montones de vidrio. Un niño canta y aplaude; otro, en la acera de enfrente dibuja el espectáculo sobre los pasquines" (p. 104). O son los absurdos ademanes de un político en una escena de mitin electoral carnavalesco convertido en masacre: "Luego se le ve gesticular, quitarse el sombrero. Se oye un chirrido... Ahora se le ve abrir y cerrar la boca, agitarse, emitir un ruido inarticulado, casi un aullido: se le ve secarse el sudor, abrir otra vez la boca" (p. 127). De ahí que la técnica del nouveau roman no sea gratuita: los objetos y detritus de la gran metrópoli son los agentes activos en la narración. Si en las novelas hispanoamericanas clásicas la selva se tragaba a los personajes, en Gestos la jungla urbana los reduce a peleles.

Pero una lectura de Gestos que no pase de este primer plano está condenada a ignorar los valores más significativos de la obra; precisamente aquellos valores que la apartan de las demás novelas cubanas de los primeros años de la década pasada, y la convierten en un texto crucial, tanto en la evolución de Sarduy como narrador, como en la evolución de la narrativa cubana. La clave para esta otra lectura de Gestos que quiero proponer se halla en su lirismo, lirismo que se contrapone, a lo largo de toda la novela, a la severa y amarga crítica que manifiesta la lectura que acabamos de indicar más arriba. Por supuesto, el lirismo de Gestos, como se verá en seguida, es de quincallería; un lirismo lleno de un patetismo trasnochado cuyo paralelo no podemos buscarlo sino en el 'arte pop', en los comic strips románticos o las novelitas rosas. Es por este 'lirismo pop' que Gestos se aparta definitivamente del nouveau roman, se vierte sobre sí misma y cifra su escritura en la de la narrativa cubana que la precede, parodiándola, interrogándola; siendo para ésta en fin, 
lo que el Quijote para la narrativa española y europea anterior al siglo XVII.

La protagonista de la novela, esa lavandera-actriz (que suponemos mulata o negra), da, desde el principio, y mantiene a lo largo de toda la novela, ese tono de lirismo patético, sostenido, sobre todo, por la aventura amorosa que constituye el móvil secreto de la acción. Porque las peripecias de la lavandera-actriz convertida en terrorista, los riesgos a que se expone para dinamitar la planta eléctrica (que forma el núcleo del argumento), no son motivados por ideales políticos, sino por un amor: "Claro que no --dice ella-, poner una bomba no es difícil. Yo pondré las que tí quieras" (p. 79). Amor imposible, melodramático, no sólo por el peligro a que está expuesto el amante, un guerrillero urbano perseguido por la policía, sino sobre todo porque, según queda sugerido, hay batreras raciales que se interponen entre ambos: "Ella se dirige [al cantar] especialmente a un muchacho blanco que siempre está sentado próximo a la pista y que después la espera cuando, ya casi en la mañana, el bar se va quedando vacío. Fue un día en que él no vino que ella interrumpió para hablar de su dolor de cabeza y su doble personalidad" (p. 14, el subrayado es mío). Notamos después un franco tono de condescendencia, de burla solapada de sus aspiraciones teatrales, cuando los cómplices del amante le dan las instrucciones necesarias para la voladura de la planta eléctrica: "Esta es su gran oportunidad para hacer teatro. Ya ve que se lo había anunciado. Eso sí, hay que ac. tuar natural, como usted dice" (página 76). Es este amor imposible de la pobre criada-actriz (con sus claras resonancias de novelista rosa) lo que socava toda la solemnidad que el episodio revolucionario pueda tener. Este aspecto de la obra queda acentuado por retazos de románticos boleros que ella canta u oye por las calles de La Habana, con todo lo cual anticipa Sarduy procedimientos luego explotados más detenidamente por Manuel Puig en Boquitas pintadas. (Por una de esas ironías a que la literatura debe tenernos ya acostumbrados, Gestos aparecerá pronto en España en forma de telenovela, que es como si Corín Tellado decidiera hacer un verdadero folletín de la novela de Puig).

El patetismo se manifiesta además en la descripción visual de los objetos, y es aquí precisamente que Gestos se aparta de Robbe-Grillet y el nouveau roman. En su magistral ensayo sobre la obra de este último, Roland Barthes ha destacado cómo en sus obras el tiempo se expresa mediante una mutabilidad "dont le processus est invisible: un objet, décrit une première fois à un moment du continu romanesque, reparait plus tard, muni d'une différence à peine perceptible... Le temps déboite 
l'espace et constitue l'objet comme une suite de tranches qui se recouvrent presque completement les unes les autres: c'est dans ce 'presque' spatial qui git la dimension temporelle de l'objet." 16 Por ello, en Robbe-Grillet: "I.'institution optique de l'objet est donc la seule qui puisi comprendre dans l'objet un temps oublié, saisie par ses effets, non par sa durée, c'est-a-dire privé de pathétique."17 En Gestos, por el contrario, se pone de relieve lo patético al permitir la sucesión no parcelada de imágenes visuales, que hacen resaltar de manera grotesca el devastador pasar del tiempo. Esta degradación del objeto se lleva a cabo mediante el empleo de dos elementos destructores - el calor y el agua- que llegan a convertirse en metáforas del tiempo. Nótese, por ejemplo, en las siguientes citas, cómo las formas activas del verbo en presente, acentúan la duración del proceso de desgaste producido por el agua:

Las líneas negras, el agua a borbotones rompiendo contra el piso los pies mojados. Sobre el libreto, la tinta de los textos se va la. vando, desdibujando. Gotas violáceas mancban la carátula (p. 31). A lo largo de los contenes el agua rueda arrastrando papeles y pieles, desaparece en remolinos en los tragantes de las esquinas o se acumula detenida por grupos de piedra. La tinta de la tipografía deja sobre el pavimento las manchas de los titulares aún adivinables, y la reproducción monstruosa de las figuras grabadas. Cuando los autos pasan, las ruedas proyectan grandes bloques de agua contra los muros y las páginas de los periódicos quedan fijas a la parte baja de las fachadas, donde el agua entintada cborrea formando sucios lamparones (p. 45).

El calor desempeña la misma función desgastadora:

Afuera debe haber sol. Afuera debe haber calor y el asfalto, aun un poco blando, recién echado sobre las piedras de la calle, debe de estar reverberando y sentirse gomoso bajo las suelas (pp. 28-29).

La labor destructora de esos dos agentes también se ejerce sobre la protagonista, que se queja constantemente de la condición de sus manos, dañadas por el agua del lavado y por el calor:

Ah, qué calor; el calor ambiente y el de los focos. Dos calores en uno. Un doble calor. Uno frente a otro, mirándose. Los dos sobre

16 Essais critiques (Paris: Editions du Seuil, 1964), p. 36.

17 Ibid., p. 37. 
la pista, sobre la pista misma, sobre mi cabeza siempre. Sobre mis manos y mis uñas, que son un asco (p. 17).

Todo el día lavando. Si, lavando. Una artista lavando; yo lavando. Cantante, actriz y lavandera... Miren qué manos para guantes, miren qué uñas para salir a la escena... (p. 13).

Ahora bien, la importancia de Gestos no reside en última instancia ni en el plano referencial ni en su habilidoso empleo del arte popular, sino en su relación con la narrativa cubana que la precede. La peculiaridad fundamental de la novela de Sarduy es el ser casi una summa de los tópicos de ésta; una especie de compendio bufo de situaciones y personajes explotados constantemente por la novelística cubana: los carnavales, los negros, la cantante, el revolucionario, el bar, el cabaret, y en el plano de la acción, la huida, la persecución, en fin, ... el acoso; en el trasfondo de Gestos, deformados pero reconocibles, se asoman los rostros de Lydia Cabrera, Lino Novás Calvo, Alejo Carpentier... Deformados porque lo significativo de Gestos es que recopila todos esos tópicos para instalarlos en el espacio narrativo degradado, en la mustia tristeza tropical que acabo de señalar. La distorsión paródica resultante libera todos esos tópicos de su valor referencial, desenmascarándolos, o sea, escamoteando las caras tras las máscaras, mostrando que los tópicos son máscaras por cuyos agujeros no se ven ojos sino un vacío oscuro y profundo. Lo irrisorio estriba en el acto de prestidigitación mediante el cual el escritor, como el mago con su sombrero de copa, produce una ruptura en el orden para revelar un vacío, que vuelve a llenar con un fugaz juego de manos, de palabras uno, de palomas el otro. El procedimiento utilizado por Sarduy puede observarse confrontando Gestos con $\mathrm{El}$ acoso de Alejo Carpentier; Gestos es $E l$ acoso (como el Quijote es el Amadís de Gaula), pero narrado, no desde el punto de vista del perseguido estudiante de arquitectura, sino desde el de Estrella, la prostituta que visitan el protagonista y el Taquillero.

Ignoro si Sarduy conocía ya al escribir Gestos el siguiente texto del formalista ruso J. Tynianov (que no fue dado a conocer en francés sino hasta 1965, pero que su traductor y editor, Tzevetan Todorov, del grupo Tel Quel, pudo haber difundido entre sus amigos), o si la relación que guarda esta novela con la narrativa cubana que la precede simplemente corrobotar la validez general de lo postulado en él:

Quand on parle de la tradition ou de la succession littéraire, on imagine généralement une ligne droite qui relie les cadets d'une 
certaine branche littéraire à leurs ainés. Pourtant les choses son beaucoup plus complexes. Ce n'est pas la ligne droite qui se prolonge, mais on assiste plutot à un départ qui s'organise à partir d'un certain point que l'on réfute... Toute succession littéraire est avant tout un combat, c'est la destruction d'un tout déjà existant et la nouvelle construction qui s'effectue à partir des éléments anciens. ${ }^{18}$

Gestos representa, pues, para la narrativa cubana, una ruptura, y para Sarduy el parricidio ritual necesario, ineludible, sin el cual no habría podido ganar entrada en ese círculo mismo contra el que dirige su agresión simbólica. ${ }^{29}$

Cornell University

Roberto González ECHEVARría

18 Citado por B. Eikhenbaum en: "La théorie de la «methode formelle»", Thiorie de la littérature, textes des formalistes, russes réunis, présentés et traduits par Tzvetan Todorov (París: Editions du Seuil, 1965), p. 68. Otro texto citado por Eikhenbaum que sirve para completar esta idea es el siguiente de V. Chklovski: "L'oeuvre d'art est perçue en relation avec les autres oeuvres artistiques et à l'aide d'associations qu'on fait avec elles... Non seulement le pastiche, mais toute oeuvre d'art est crée en parallèle et en opposition à un modele quelconque. La nouvelle forme n'apparait pas pour exprimer un contenu nouveau, mais pour remplacer l'ancienne forme qui a déjà perdu son caractère esthétique". Ibid., p. 50.

10 Este artículo forma parte parte de un estudio más extenso en preparación sobre la obra de Severo Sarduy. 